\title{
ATTENUATION OF HAEMODYNAMIC RESPONSES TO LARYNGOSCOPY AND INTUBATION - A COMPARATIVE STUDY BETWEEN IV ESMOLOL AND IV DEXMEDETOMIDINE
}

\author{
Maheeja Maddi Reddy1, Nagaraja A. S2 \\ ${ }^{1}$ Senior Resident, Department of Anaesthesiology, Kempegowda Institute of Medical Sciences, Bangalore. \\ ${ }^{2}$ Associate Professor, Department of Anaesthesiology, Kempegowda Institute of Medical Sciences, Bangalore.
}

\section{ABSTRACT}

\section{BACKGROUND}

Laryngoscopy and tracheal intubation in adults cause stress response manifested by a rise in heart rate and blood pressure. Intravenous Esmolol has been used to suppress this stress response. A highly selective $\alpha 2$ adrenoreceptor agonist, Dexmedetomidine is being increasingly used to attenuate this response. In this clinical comparative study, we compared these two drugs in attenuating the stress response to laryngoscopy and intubation.

\section{MATERIALS AND METHODS}

100 patients belonging to ASA1 and ASA2 posted for surgeries under general anaesthesia were randomly divided into 2 groups of 50 each. Both the groups were pre-medicated with Inj. Glycopyrrolate $0.005 \mathrm{mg} / \mathrm{kg}$ and Inj. Fentanyl $1.5 \mu \mathrm{g} / \mathrm{kg}$ was given. Group D

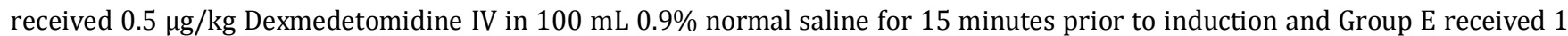
$\mathrm{mg} / \mathrm{kg}$ bolus dose of Esmolol 90 seconds prior to intubation. Both groups were induced with 2.5\% Thiopentone $5 \mathrm{mg} / \mathrm{kg}$ and Inj. Vecuronium $0.1 \mathrm{mg} / \mathrm{kg}$. Laryngoscopy was done and intubation accomplished within 20 seconds. Heart rate, blood pressure, mean arterial pressure were recorded before induction (baseline) and at every minute for the first 5 minutes and at 10,15, 30 and 45 mins. after intubation. Sedation scoring as per modified Ramsay sedation scale was noted after extubation in both the groups. Statistical analysis was done using Chi-square $(\chi 2)$ test of significance and Student " $t$ " test and P value obtained.

\section{RESULTS}

Both groups showed attenuation of stress response. Esmolol and Dexmedetomidine affected heart rate to same extent upto 5 minutes ( $p>0.05)$. Unlike Esmolol group, heart rate remained lower in Dexmedetomidine group even after 10 minutes. In Dexmedetomidine group there was increase in SBP, DBP and MBP upto 3 minutes, after that it was maintained below the baseline. In Esmolol group there was no rise in systolic and diastolic blood pressure, mean arterial blood pressure and rate pressure product compared to the baseline from the 1 st minute of intubation which is statistically significant $(p<0.0001)$. Post extubation Dexmedetomidine group patients were more sedated than those in Esmolol group.

\section{CONCLUSION}

Both Esmolol and Dexmedetomidine attenuate the stress response to laryngoscopy and intubation. When both these drugs were compared, Esmolol attenuated the stress response to laryngoscopy and intubation better than Dexmedetomidine and afforded a good haemodynamic stability. Post extubation Dexmedetomidine group patients were more sedated than those in Esmolol group.

\section{KEYWORDS}

Anaesthesia, Haemodynamic, Esmolol, Dexmedetomidine, Laryngoscopy, Intubation.

HOW TO CITE THIS ARTICLE: Reddy MM, Nagaraja AS. Attenuation of haemodynamic responses to laryngoscopy and intubation a comparative study between IV esmolol and IV dexmedetomidine. J. Evolution Med. Dent. Sci. 2016;5(85):6313-6317, DOI: 10.14260/jemds/2016/1426

\section{BACKGROUND}

Laryngoscopy and endotracheal intubation are associated with physical trauma to the oral cavity and elicit physiological response in the form of sympathoadrenal response seen in adults and vago-vagal reflex predominantly seen in children. ${ }^{1}$

The induction of anaesthesia, laryngoscopy, intubation and surgical stimulation often evoke cardiovascular responses characterised by alterations in systemic blood pressure, heart rate and cardiac rhythm.2,3 The response following

Financial or Other, Competing Interest: None.

Submission 16-09-2016, Peer Review 10-10-2016,

Acceptance 18-10-2016, Published 21-10-2016.

Corresponding Author:

Dr. Maheeja Maddi Reddy,

D/o. M. S. Reddy, SA 4, Magan Samara Mews,

Panduranga Nagar, J. P. Nagar 7th Phase,

Off Bannerghatta Road, Bangalore-560076.

E-mail: drmaheeja15@gmail.com

DOI: $10.14260 /$ jemds/2016/1426 laryngoscopy and intubation peaks at 1-2 minutes and returns to baseline within 5-10 minutes.

Complications like left ventricular failure, myocardial ischaemia and cerebral haemorrhage have been attributed to sudden rise in systemic arterial blood pressure and increase in heart rate. ${ }^{4}$ Increase in intraocular and intracranial pressure is also noted.

These complications are more likely to occur in patients with preexisting hypertension, coronary heart diseases, cerebral vascular diseases, intracranial pathology and hyperactive airways. In such cases, reflex circulatory responses such as increase in heart rate, systemic arterial blood pressure and disturbances in cardiac rhythm need to be suppressed.

Many strategies have been advocated to minimise these haemodynamic adverse responses and are aimed at different levels of the reflex arc. 


\section{The Common Strategies Adapted are}

- $\quad$ Shortening the duration of laryngoscopy to less than 15 seconds.

- Use of narcotics, vasodilators, beta blockers, calcium channel blockers, lidocaine and other sympatholytics.

Esmolol is the most commonly used $\beta$ blocker; it is a cardio-selective $\beta$ blocker with rapid onset and short duration of action. It reduces resting heart rate, systolic blood pressure, ejection fraction and cardiac index but it maintains the coronary perfusion pressure.

Dexmedetomidine, a highly selective $\alpha_{2}$ adrenoreceptor agonist, possesses hypnotic, sedative, anxiolytic, sympatholytic properties that blunt many of the cardiovascular responses in the perioperative period and produces analgesia without causing significant respiratory depression. It has an eight-fold greater affinity to $\alpha_{2}$ adrenergic receptors than Clonidine and much less $\alpha_{1}$ effect.

Dexmedetomidine has been used widely in anaesthesia as a premedicant analgesic to attenuate sympathetic response to surgery in the perioperative period and to potentiate the anaesthetic effects of all intraoperative anaesthetics. ${ }^{5}$

\section{OBJECTIVES}

1. To compare the effects of intravenous Dexmedetomidine and intravenous Esmolol on haemodynamic response to laryngoscopy and intubation in relation to,

- $\quad$ Heart Rate (HR).

- $\quad$ Blood pressure - systolic and diastolic (SBP, DBP).

- Mean Arterial Pressure (MAP).

- $\quad$ Rate Pressure Product (RPP).

2. To ascertain the effectiveness of intravenous Dexmedetomidine $0.5 \mu \mathrm{g} / \mathrm{kg}$ over Esmolol $1 \mathrm{mg} / \mathrm{kg}$ or vice versa in attenuating haemodynamic response to laryngoscopy and endotracheal intubation.

\section{MATERIALS AND METHODS}

100 patients of ASA physical status I and II aged between 1850 years undergoing elective surgical procedure under General Anaesthesia with endotracheal intubation were included in the study.

\section{Inclusion Criteria}

1. Patients belonging to ASA grade 1 and 2.

2. Age group from 18-50 years of both sexes.

3. Weighing between $50-70 \mathrm{~kg}$.

4. Mallampati Class I and II.

5. Patients posted for various elective surgical procedures in which general anaesthesia is required.

\section{Exclusion Criteria}

1. History of allergy to either Dexmedetomidine or Esmolol.

2. Predicted difficulty in intubation, pregnancy, nursing women and morbid obesity.

3. Coronary artery diseases, ischaemic heart diseases, heart blocks.

4. Patients with history of diabetes mellitus, hypertension, renal dysfunction, hepatic dysfunction.

5. Asthma, anaemia, endocrinal diseases, muscle dystrophy and burns.

\section{Method of Collection of Data}

Pre-anaesthetic evaluation was done on the evening before surgery, assessing general condition of the patient. A detailed examination of the cardiovascular and respiratory system was done. Routine blood investigations were done in all patients including chest X-ray and ECG in indicated cases.

Patients were divided randomly into two groups (Group D and Group E) of fifty each using computer generated random numbers table and informed consent was obtained.

Group D - Dexmedetomidine group received.

Dexmedetomidine $(0.5 \mathrm{mcg} / \mathrm{kg})$.

Group E - Esmolol group received Esmolol (1.0 mg/kg).

\section{Premedication}

Patients were given a premedication of Tab. Alprazolam 0.5 $\mathrm{mg}$ and Tablet Ranitidine $150 \mathrm{mg}$ orally a night prior to surgery and on the morning of surgery at 6:00 am with sips of water. All patients were advised to be nil by mouth for 8 hours before the surgery.

In the pre-operative room, an intravenous line was secured with 18G cannula and infusion of lactated ringer's solution was given constantly at a rate of $5 \mathrm{~mL} / \mathrm{kg} / \mathrm{hr}$ throughout the study.

In the operating room, anaesthesia machine check drill (cockpit drill) was performed and on receiving the patient's pulse oximeter ECG, non-invasive blood pressure from a Datex Ohmeda monitor was connected. Baseline haemodynamic parameters - HR and BP were noted.

Group D received $0.5 \mu \mathrm{g} / \mathrm{kg}$ Dexmedetomidine IV in 100 $\mathrm{mL} 0.9 \%$ normal saline for 15 minutes prior to induction and Group E received $1 \mathrm{mg} / \mathrm{kg}$ bolus dose of Esmolol 90 seconds prior to intubation.

HR, SBP, DBP and MBP were recorded non-invasively during administration of study drug, during induction and every minute for the first 5 minutes and at 10 minutes, 15 minutes, 30 minutes and 45 minutes following intubation.

\section{Induction}

Both the groups were given Inj. Glycopyrrolate $0.005 \mathrm{mg} / \mathrm{kg}$ and Inj. Fentanyl $1.5 \mathrm{ug} / \mathrm{kg}$, during which patient was preoxygenated with $100 \%$ oxygen. General anaesthesia was induced with Inj. Thiopentone $2.5 \%$ solution at $5 \mathrm{mg} / \mathrm{kg}$. After a time interval of 1 minute, a long-acting muscle relaxant Inj. Vecuronium $0.1 \mathrm{mg} / \mathrm{kg}$ was given intravenously and ventilation continued for 3 more minutes.

\section{Laryngoscopy and Intubation}

At the end of 3 minutes, gentle laryngoscopy was performed using Macintosh blade and appropriate sized cuffed oral endotracheal tube was passed within 20 seconds. Bilateral air entry was confirmed by auscultation and $\mathrm{EtCO}_{2}$ was connected and cuff was inflated with appropriate volume of air and the endotracheal tube was fixed with adhesive tapes.

\section{Maintenance of Anaesthesia}

Anaesthesia was maintained with $33 \%$ oxygen and $66 \%$ nitrous oxide for up to 5 minutes after endotracheal intubation. Heart rate and blood pressure monitoring was done every minute for first five minutes. Surgery was withheld and positioning, painting, draping and packing of throat were not done during the study period.

After the study period of 5 mins, inhalational agent Isoflurane and narcotic analgesics were supplemented titrating to the respective case and neuromuscular blockade 
was maintained with Inj. Vecuronium $0.05 \mathrm{mg} / \mathrm{kg}$. Similar monitoring was done at 10,15, 30 and 45 minutes following intubation.

Patients were monitored for adverse effects of drugs like hypotension, bradycardia, any dysrhythmia and other anaesthesia related problems and were attended promptly.

After the surgical procedure patients of both groups were reversed with Inj. Neostigmine $0.05 \mathrm{mg} / \mathrm{kg}$ and Inj. Glycopyrrolate $0.01 \mathrm{mg} / \mathrm{kg}$ given intravenously.

Sedation scoring was recorded as per modified Ramsay sedation scale after extubation.

\section{RESULTS}

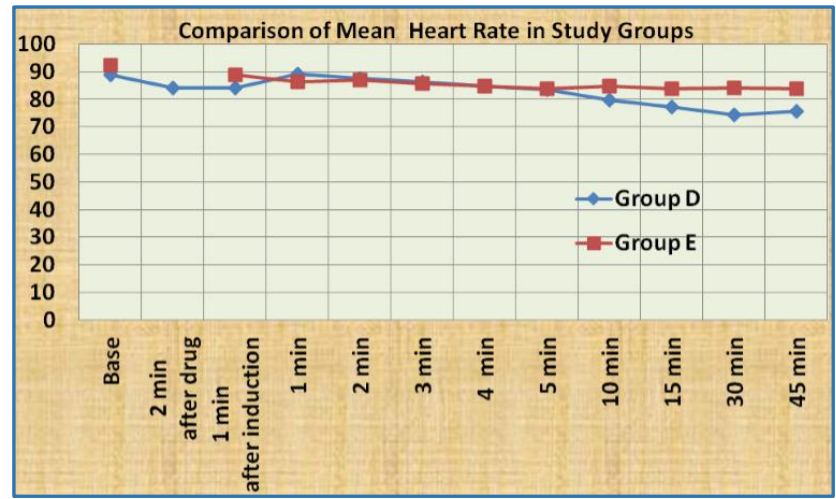

\section{Graph 1. Comparison of Heart}

Rate in Two Groups of Patients

We observed that HR increased in Dexmedetomidine group at 1 minute, i.e. $89.08 \pm 12.876$. After 1 minute, there was fall in the HR compared to the baseline. Whereas in the Esmolol group, there was no increase in the HR as compared to baseline and HR was consistently lower compared to baseline from 1 min to 5 mins.

Heart rate continued to remain lower in the Dexmedetomidine group even after 5 minutes.

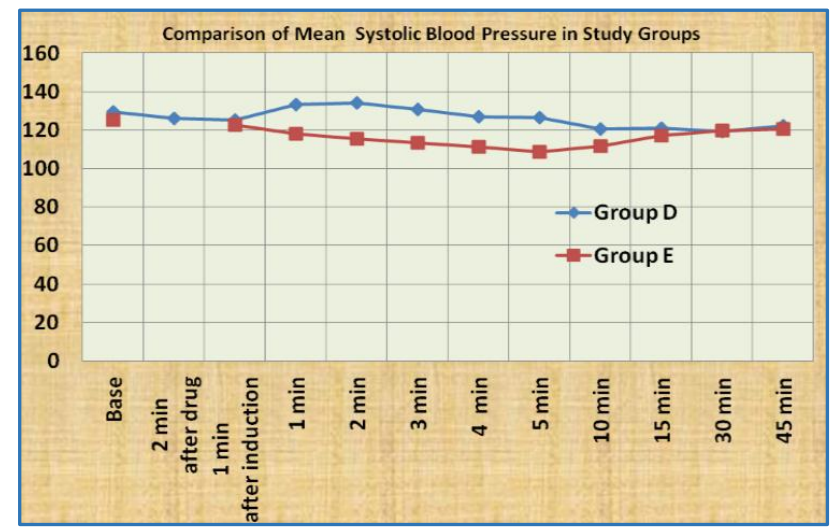

Graph 2. Comparison of Systolic BP (mmHg) in Two Groups of Patients

In the Group D there was an increase in the mean SBP of the patients at 1, 2 and 3 minutes and after that the SBP was maintained below the baseline. Whereas in the Group E, there was no rise in mean SBP compared to the baseline right from the $1^{\text {st }}$ minute of intubation.

Esmolol is more effective in suppressing the rise in SBP compared to Dexmedetomidine up to 15 minutes following intubation ( $p<0.0001$ at $1,2,3,4$ and 5 mins, $p=0.0012$ at 10 mins).

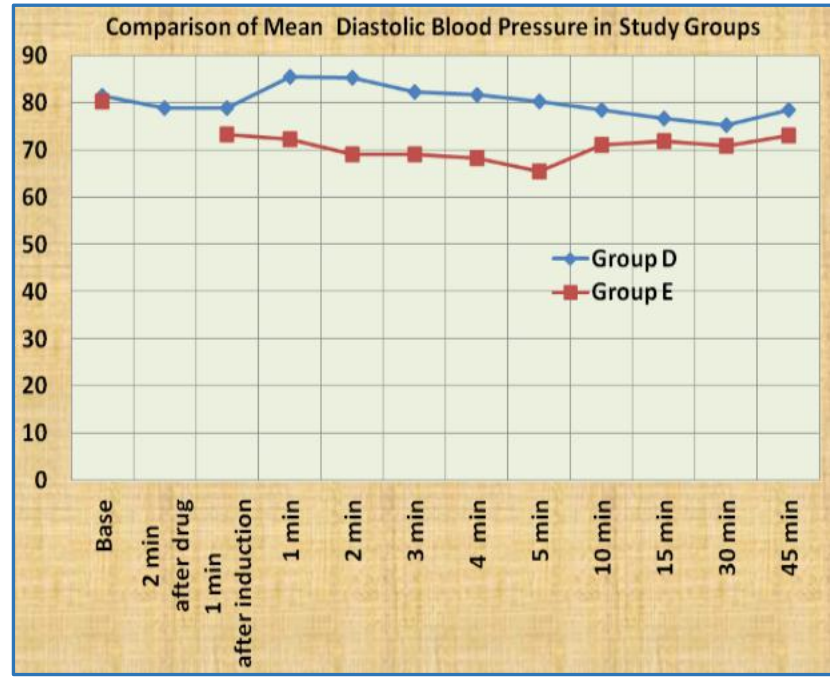

Graph 3. Comparison of Diastolic BP ( $\mathrm{mmHg}$ ) in Two Groups of Patients

In the Group D, there was an increase in the mean DBP of the patients at 1, 2, 3 and 4 minutes and after that the DBP was maintained below the baseline. Whereas in the Group E, there was no rise in mean DBP compared to the baseline right from the $1^{\text {st }}$ minute of intubation.

Esmolol is more effective in suppressing the rise in DBP compared to Dexmedetomidine following intubation $(\mathrm{p}<$ 0.0001 at $1,2,3,4,5$ and 10 mins, $p=0.0105$ at 15 mins, $p=$ 0.0204 at 30 mins and $p=0.0038$ at 45 mins).

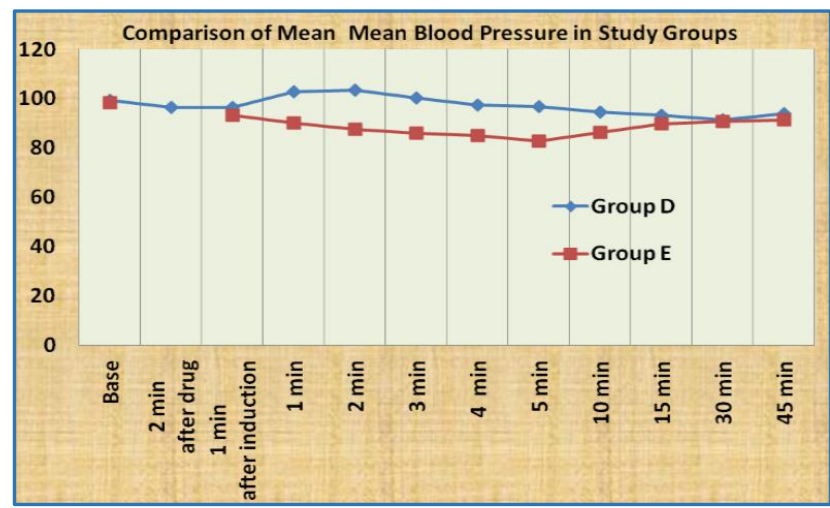

Graph 4. Comparison of MAP

(mmHg) in Two Groups of Patients

In the Group D, there was an increase in the mean MBP of the patients at 1, 2 and 3 minutes and after that the MBP was maintained below the baseline. Whereas in the Group E, there was no rise in mean MBP compared to the baseline right from the $1^{\text {st }}$ minute of intubation.

Hence, Esmolol is more effective in suppressing the rise in MBP compared to Dexmedetomidine following intubation ( $\mathrm{p}<$ 0.0001 at $1,2,3,4,5$ and 10 mins). 


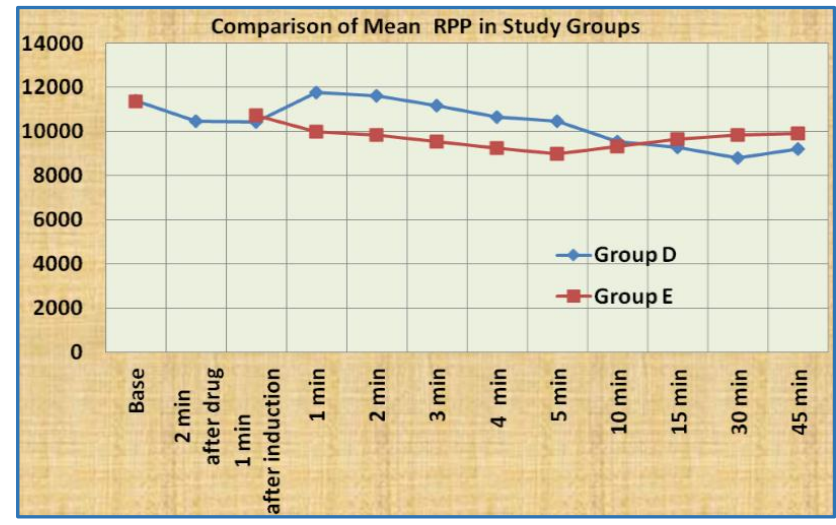

Graph 5. Comparison of Rate Pressure Product in Two Groups of Patients

In the Dexmedetomidine group, the mean RPP increased in the $1^{\text {st }}$ and $2^{\text {nd }}$ minute after intubation and has persistently remained below the baseline after that. Whereas in the Esmolol group, the mean RPP persistently remained below the baseline right from the $1^{\text {st }}$ minute.

Hence, the RPP in patients in Group E is significantly lower compared to the patients in Group D ( $p<0.0001$ at 1,2 and 3 mins, $\mathrm{p}=0.0009$ and $\mathrm{p}=0.0003$ at 4 and 5 minutes respectively).

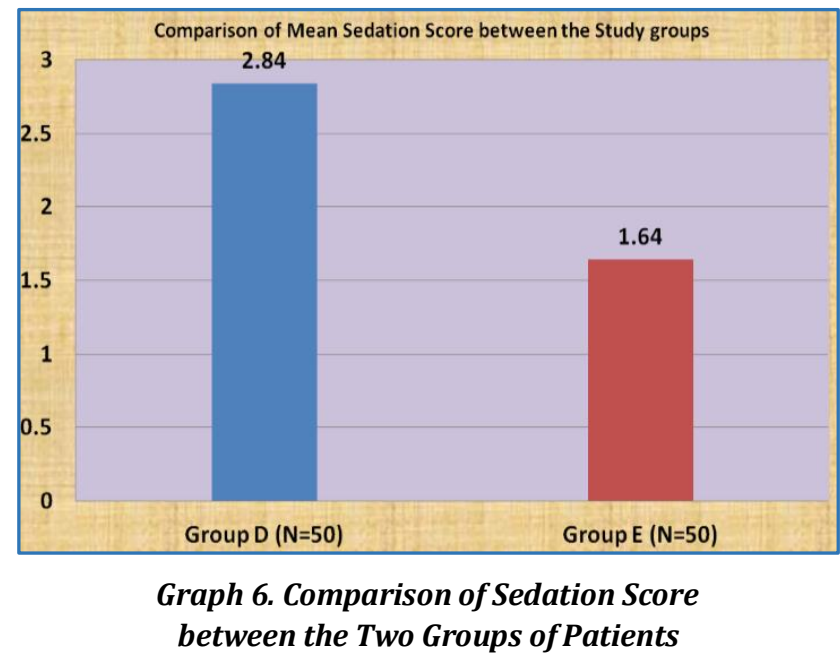

We found that there is significant difference in post extubation sedation level of the patients of the two groups, in that patients in the Dexmedetomidine group were more sedated than those in Esmolol group ( $p<0.0001)$.

\section{DISCUSSION}

This study was done to compare the relative efficacies of IV Dexmedetomidine and IV Esmolol in suppressing the haemodynamic response to intubation in normotensive population. There were no significant differences between two groups in age, body weight, gender and ASA grading. Basal Heart Rate (HR), Systolic Blood Pressure (SBP), Diastolic Blood Pressure (DBP) and Mean Arterial Pressure (MAP) were not statistically significant $(p>0.05)$ in both groups.

Hale Yarkan Uysal,6 Esma Tezer and Müge Türkoğlu, in their study compared the effects of Esmolol, Dexmedetomidine and Sufentanil on haemodynamic responses to tracheal intubation in hypertensive patients scheduled for non-cardiac surgery under general anaesthesia.
Groups E, D and S respectively received esmolol (100 mg) dexmedetomidine $(1 \mu \mathrm{g} / \mathrm{kg})$ and sufentanil $(0.25 \mu \mathrm{g} / \mathrm{kg})$. According to the mean percentage variation, a significant reduction in HR was assessed in Group D compared to Group $\mathrm{S}$ and Group E. Increment in SBP was significant in Group E when compared to Group D. Increment in DBP in Group S was significant compared to Group D. Median thiopental dose was significantly lower in Group D compared to Group E and Group S. They concluded that in hypertensive patients, administration of Dexmedetomidine before anaesthesia induction blunts the haemodynamic response to tracheal intubation and reduces the thiopental dose.

Siddareddigari Velayudha Reddy, ${ }^{7}$ Donthu Balaji and Shaik Nawaz Ahmed did a study on Dexmedetomidine versus Esmolol to attenuate the haemodynamic response to laryngoscopy and tracheal intubation. The patients were randomly divided into three groups $(n=30)$. Group $C$ received placebo, Group E received $2.0 \mathrm{mg} / \mathrm{kg}$ of Esmolol and Group D received $1.0 \mu \mathrm{g} / \mathrm{kg}$ of Dexmedetomidine, intravenously over 10 mins. and 3 mins. before induction of general anaesthesia. The mean increase in HR was minimal 5.83\% in Group D when compared with Group E 14\% and Group C 30\%. The mean SBP and DBP levels in Group D were significantly lower than Groups $\mathrm{C}$ and $\mathrm{E}$ immediately after intubation and until the end of surgery. The MAP rose by 30\% in Group C, 26\% in Group E and only $2 \%$ in Group D at intubation. In this study, the rise in mean RPP was least in Group D and highest in Group C. They concluded that the suppression in cardiovascular responses was found to be greater with Dexmedetomidine than that resulted from infusion of Esmolol $2.0 \mathrm{mg} / \mathrm{kg}$.

In contrast to the previously mentioned studies, we did not detect any excessive reduction in HR or blood pressure values in the dexmedetomidine group compared to Esmolol. In our study, IV Dexmedetomidine $(0.5 \mathrm{mcg} / \mathrm{kg})$ given prior to induction failed to attenuate the heart rate to the same extent as Esmolol (1 mg/kg) during laryngoscopy and endotracheal intubation and thereafter.

Results from our study consistently showed Bolus injection of Esmolol $(1 \mathrm{mg} / \mathrm{kg})$ given 90 seconds prior to intubation provided consistent and reliable protection against increases in mean heart rate and blood pressure during laryngoscopy and endotracheal intubation.

Our findings are in agreement with that of Singh $\mathrm{H}$, Vichitvejpaisal $\mathrm{P}^{8}$ et al who compared the effects of the Lidocaine, Esmolol and Nitroglycerin and showed Lidocaine $1.5 \mathrm{mg} / \mathrm{kg}$ IV and Nitroglycerin 2 micrograms/kg IV were ineffective in controlling the acute haemodynamic response following laryngoscopy and intubation. Esmolol $1.4 \mathrm{mg} / \mathrm{kg}$ IV was significantly more effective than either Lidocaine or Nitroglycerin in controlling the HR response to laryngoscopy and intubation $(\mathrm{p}<0.05)$.

Kumar $^{9}$ et al in 2003 have reported optimal results, while using higher doses of Esmolol $(2 \mathrm{mg} / \mathrm{kg}$ ) in an Asian population without any incidence of unplanned hypotension or bradycardia. In this normotensive cohort of population, Esmolol at a dose of $2 \mathrm{mg} / \mathrm{kg}$ effectively decreased HR, SBP, DBP, MAP and RPP without any incidence of hypotension or bradycardia. This study further observed a reduction in DBP less than that in SBP resulting in a better control of the MAP in the study population. Increases in heart rate of patients receiving Esmolol in this study was attenuated as compared to the control group for a maximum duration of 5 minutes after intubation. 
In our study, we also found that there is significant difference in post extubation sedation level of the patients of the two groups, in that patients in the Dexmedetomidine group were more sedated than those in Esmolol group ( $<<0.0001)$.

Our findings correspond with that of Shams $\mathrm{T}^{10}$ et al who concluded in their study on induced hypotension for functional endoscopic sinus surgery: A comparative study of dexmedetomidine versus esmolol that the sedation score were significantly lower in Esmolol group compared with Dexmedetomidine group at 15 and 30 minutes postoperatively.

From our study we can infer that Dexmedetomidine did cause some amount of sedation, but the sedation was also not that severe so as to warrant any interference from our side.

\section{CONCLUSION}

Based on our Present Comparative Study the following Conclusions were Drawn

1. Intravenous Esmolol significantly attenuates the haemodynamic response to laryngoscopy and intubation.

2. Esmolol is more effective than Dexmedetomidine in attenuation of sympathetic response to laryngoscopy and intubation.

3. Intravenous Esmolol $1 \mathrm{mg} / \mathrm{kg}$ administered 90 seconds prior to laryngoscopy and intubation can be recommended to attenuate the haemodynamic stress response to laryngoscopy without any side effects of the drug.

4. Post extubation Dexmedetomidine group patients were more sedated than those in Esmolol group.

\section{REFERENCES}

1. Hageberg CA. Benumof's airway management. $2^{\text {nd }}$ ed. Hageberg: Mosby Elsevier 2007.

2. King BD, Harris LC, Greifenstein FE, et al. Reflex circulatory responses to direct laryngoscopy and tracheal intubation performed during general anaesthesia. Anaesthesiology 1951;12(5):556-66.
3. Moffit EA, Sethna DH, Bussel JA, et al. Effects of intubation on coronary blood flow and myocardial oxygenation. Can Anaesth Soc J 1985;32(2):105-11.

4. Fox EJ, Sklar GS, Hill CH, et al. Complications related to the pressor response to endotracheal intubation. Anesthesiology 1977;47(6):524-5.

5. Derbyshire DR, Smith G. Sympatho adrenal responses to anaesthesia and surgery. Br J Anaesth 1984;56(7):72539.

6. Uysal HY, Tezer E, Türkoğlu M. The effects of dexmedetomidine on hemodynamic responses to tracheal intubation in hypertensive patients: a comparison with esmolol and sufentanyl. J Res Med Sci 2012;17(1):22-31.

7. Reddy SV, Balaji D, Ahmed SN. Dexmedetomidine versus esmolol to attenuate the hemodynamic response to laryngoscopy and tracheal intubation: a randomized double-blind clinical study. Int J Appl Basic Med Res 2014;4(2):95-100.

8. Singh H, Vichitvejpaisal P, Gaines GY, et al. Comparative effects of lidocaine, esmolol, and nitroglycerin in modifying the hemodynamic response to laryngoscopy and intubation. J Clin Anesth 1995;7(1):5-8.

9. Kumar S, Mishra MN, Mishra LS, et al. Comparative study of the efficacy of i.v. esmolol, diltiazem and magnesium sulphate in attenuating hemodynamic response to laryngoscopy and tracheal intubation. Indian J Anaesth 2003;47(1):41-4.

10. Shams T, El Bahnasawe NS, Abu-Samra M, et al. Induced hypotension for functional endoscopic sinus surgery: a comparative study of dexmedetomidine versus esmolol. Saudi J Anaesth 2013;7(2):175-80. 